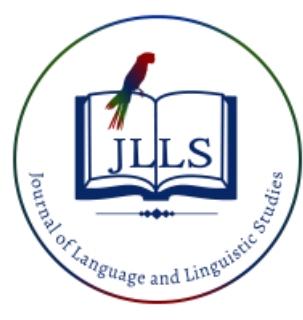

Available online at www.jlls.org

JOURNAL OF LANGUAGE AND LINGUISTIC STUDIES

ISSN: 1305-578X

Journal of Language and Linguistic Studies, 17(1), 421-430; 2021

\title{
Research of peculiarities of speech of male and female on phonetic and lexical
}

\author{
levels of language
}

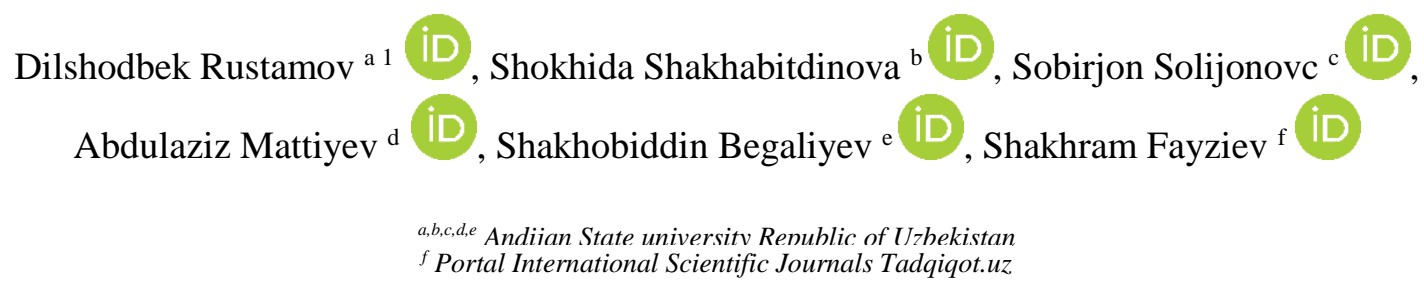

\section{APA Citation:}

Rustamov, D., Shakhabitdinova, S., Solijonovc, S., Mattiyev, A., Begaliyev, S., \& Fayziev, S. (2021). Research of peculiarities of speech of male and female on phonetic and lexical levels of language. Journal of Language and Linguistic Studies, 17(1), 421-430. Doi: $10.52462 / \mathrm{jl} 1 \mathrm{~s} .26$

Submission Date: 04/01/2021

Acceptance Date: 10/03/2021

\begin{abstract}
Gender differences are manifested not only in the physiological characteristics of a person, but also in the speech communication. This article presents the research data obtained at the phonetic and lexical levels of the language. The purpose of this work is to determine the speech characteristics that distinguish men and women at the studied language levels. The identification of the peculiarities of the speech of men and women supplements and clarifies the results of research in the field of gender studies. Before beginning the discussion on the specifics of male and female speech, it is important to understand what gender linguistics is and to learn a little about the history of this study. Until recently, linguists focused only on studying the differences in languages that were related to differences between groups of people (psycholinguistics, ethno linguistics, socio linguistics). But no one paid attention to the gender difference of the speech. Only recently have linguists begun to pay attention to the peculiarities of male and female speech.
\end{abstract}

Keywords: gender; socio-sex communication; differences between male and female speech; sociolinguistics; speech; peculiarities.

\section{Introduction}

The purpose of this work is to determine the speech characteristics that distinguish men and women at the studied levels of the language. The identification of the peculiarities of the speech of men and women supplements and clarifies the results of research in the field of gender studies. The significant thing that recognizes individuals from creatures is fundamentally our approach to speak with one another by utilizing language. We have words for explicit things, feelings, and articulations. In every language, words are built with a particular goal in mind and the method of communicating those words has gotten unique. Through time society has gone through extraordinary changes which have impacted

\footnotetext{
${ }^{1}$ Corresponding author.

E-mail address: drustamov.asu@yahoo.com
} 
our speeches. New vocabularies have been added and simultaneously antiquated words have been supplanted. Every language has its qualities which mirror the general public in an incredible degree.

Gender orientation distinction has gone into linguistics as a phonetic variable for quite a while. The connection among language and sex has gotten one of the significant issues in sociolinguistics since mid 1970s [10]. In our advanced society, doubtlessly women are equivalent with men. Nonetheless, the brutal reality discloses to us that women are not furnished with an equivalent chance in any event, for conversations. Presently the two genders individually order distinctive correspondence styles. In other words, the language utilized by females is not the same as the language utilized by men [3].

The utilization of language is distinctive among people if there should be an occurrence of jargon, in voice and tone, in syntactic construction and style and in conversational style. In every one of the single part sex varies in an incredible degree. In each circle of our life the thing that matters is being seen while usage of language. With regards to our country, the sex distinction is observable in a wide reach. Here, in utilizing language men contrast from ladies in an incredible degree which is critical [12]. Among every one individuals, the distinction of language usage between female and male is considered significantly.

Along these lines, the primary design is to go through their method of utilizing language and to discover the normal contrast on their discussion which reflects sex distinction. Also, the point is to discover the explanations for the distinction and to build up those reasons coherently.

\subsection{Literature review}

The relevance of the topic is dictated by the interest of modern linguistics in the problems of gender differences in language options in the research of such scientists as Khaleeva, I.I., Zemskaya E.A., Kitaygorodskaya M.A., Rozanova N.N., Gorodnikova M.D. [1,7,9], who pay attention to the features of male and female speech communication. Achieving the goal involves solving the following tasks:

- On the basis of a review of scientific literature, study the history of the emergence of the concept of "gender".

- To carry out a sociolinguistic research at the level of phonetics and vocabulary using the methods of participatory observation, a survey of university students 18-25 years old.

- To establish the types of differences between male and female communication at the phonetic and lexical levels of the language [4].

A.V. Kirilina [10], in the monograph "Gender: Linguistic Aspects", published in 1999, in the first chapter of his work pays attention to the emergence of the concept of "gender" meaning a set of social and cultural norms that society prescribes to people depending on their biological sex [10]. The gender category was introduced into the conceptual apparatus of science in the late $60 \mathrm{~s}$ - early $70 \mathrm{~s}$ of the 20th century and was used first in history, historiography, sociology and psychology, and then was adopted in linguistics [5]. Initially, work on the study of gender characteristics of speech appeared in the West, and the first systematic descriptions of male and female characteristics of speech were made on the basis of languages from the Germanic and Romance language groups. As for domestic linguistics, the first regular research on this topic began to be carried out only in the late 1980s and early 1990s [2]. And already from the mid-90s they began to develop at a rapid pace. The term gender, thus, was used to describe the social, cultural, psychological aspects of "feminine" in comparison with "masculine", that is, "while highlighting everything that forms traits, norms, stereotypes, roles, typical and desirable for those whom society defines both women and men" [11, 13]. At the same time, it is noted that in science to this day there is no single view of the nature of gender, since some scientists refer this concept to models developed for the purpose of a clearer scientific description of the problems of gender and the delineation of its biological and sociocultural functions [1, 3, 12]. Other scholars view 
gender as a social construct created by society, including through language [8]. A person's gender can be reflected in his language and speech. "Men and women speak differently, and these options do not depend on the situation: there are almost no "female situations" and "male situations" when the same person would choose one or another option at will [14]. A woman speaks differently than a man, and the listener knows how to distinguish the speech of women from the speech of men not only by the timbre of the voice. [6,7]. Of course, the speech of men and women is different, but this can only be talked about in certain tendencies in speech, since gender oppositions manifest themselves in different spheres of the language.

Researchers Zemskaya E.A. [9], Kitaygorodskaya M.A., Rozanova N.N. [17], argue that in the field of phonetics, the features of speech are manifested as follows:

- women are inherent in the predominance of vowel sounds over consonants;

- men are inherent in the predominance of consonants over vowels;

- women's emotional speech is characterized by the use of melodic modulations, while men are characterized by a special use of lexical and grammatical means.

There are sure contrasts with regards to language use by people. The investigation of how sexual orientation is reflected in language is a new part of semantics; it has created research discoveries in the mid 1960s [8]. The exploration on the connection among language and sex created on certain levels:

1) The gender difference in language form and structure;

2) The gender difference in utterance style;

3) The reasons for gender difference in language;

Some notable language specialists like Lakoff [11], Taneen, Cameron [13] investigates the reflect of sexual orientation contrasts in elocution, pitch, jargon and talk style from the point of view of sociolinguistics research, and dissect the most recent reasons of these distinctions and improvement and changes [17]. Additionally, these some notable essayists like Robin Lakoff, Deborah Taneen $[11,16]$ have given their own perspective about the hypotheses of language and sexual orientation dependent on certain methodologies [18].

\subsection{Research questions}

Do male understudies and female understudies use language contrastingly at the tertiary level?

How do they talk another way from one another?

What are the most well-known contrasts among them?

Is there any effect or impact of this variety in correspondence?

\section{Article structure}

The contents of this article consists

- Title of article;

- Authors;

- Abstract;

- Key words;

- Introduction;

- Method;

- Results;

- Discussion; 
- Conclusion;

- Acknowledgements;

- References.

\section{Research methodology}

This part contains the examination strategy that was trailed by the analyst to direct the researches. Besides, a detailed discussion on the objective of the research, the significance of the study, instruments, participants, and process of analysis has been included here. Survey comprising of different decision thing was appropriated to the understudies of various private colleges.

\subsection{Samples / Participants}

In the course of this work, a study of the characteristics of male and female speech was carried out at two levels of the modern Russian language - phonetic and lexical. Our goal was to establish the types of differences prevailing in socio-sexual communication at the studied levels of the language. The number of respondents was 40 people: 20 men and 20 women. The experiment involved men and women aged 18 to 25 years old, students of universities of the Siberian Federal District. They were presented with pictures of modern kitchen utensils used in almost every family (mixer, blender, garlic press, colander). Also, for a certain time, the method of inclusive observation was used to identify the features of speech at the phonetic level. The linguistic material of the study included etiquette words often used in verbal communication. These are words like: thank you, please, hello, goodbye.

\subsection{Instruments}

The participants were given questionnaires for conducting the survey. Printed forms of questionnaire have been distributed among the participants and all the questions were made understandable by the researcher. Therefore, the main sources of information of this research are: Survey (appendix)

\subsection{Data collection procedures}

\subsubsection{Questionnaries of Survey}

A printed structure that remembers a few inquiries for which respondents are required to compose their own considerations and convictions is known as a survey. To guarantee Questionnaire's legitimacy and unwavering quality, the meeting with the manager and the writing audit of the examination were thought about while planning the inquiries.

The surveys included 12 numerous decision questions comprising of 2 alternatives. In every one of the inquiries understudies needed to pick one explicit answer.

\section{Results}

In the field of vocabulary, there is a clear difference in the topics of conversations, this is due to the fact that men and women have different spheres of activity that influence the choice of one or another topic of conversation. In the field of grammar, women are strongly inclined to use interjections. The peculiarities in the field of syntax, the use of introductory constructions with the meaning of a high degree of confidence are distinguished by men, while women use these constructions with the meaning of uncertainty. Researchers of gender differences in speech have come to the conclusion that the communicative behavior of men is aimed at self-affirmation, the fulfillment of social tasks, concentration and purposefulness. And the communicative behavior of women, on the contrary, is 
aimed at the inner world, the comfort of communication, carelessness and the expression of their own feelings and emotions. A woman seeks to adapt to the conditions that are dictated by the speech situation, and men actively influence the environment and try to change certain circumstances the way they plan. It is undeniable that men and women speak different languages, since they perceive the world around them in completely different ways and build their speech behavior in accordance with this perception.

For research at the lexical level, the respondents had to give the names of the kitchen utensils presented to them, in accordance with how they use them in everyday life. The data obtained are presented in Table 1 .

Table 1. Kitchen utensils in everyday life

\begin{tabular}{|c|c|c|c|c|}
\hline Words & \multirow[t]{2}{*}{ Mixer } & \multirow[t]{2}{*}{ Blender } & \multirow[t]{2}{*}{ Garlic Press } & \multirow[t]{2}{*}{ Colander } \\
\hline Gender & & & & \\
\hline Male & Mixer & $\begin{array}{l}\text { Combine } \\
\text { harvester, Blender }\end{array}$ & Garlic press & $\begin{array}{l}\text { Colander, } \\
\text { Drushlag, } \\
\text { Sieve }\end{array}$ \\
\hline Female & $\begin{array}{l}\text { Blender, } \\
\text { Whisk }\end{array}$ & $\begin{array}{l}\text { Mixer, } \\
\text { Blender, } \\
\text { Juicer, } \\
\text { Coffee grinder }\end{array}$ & Garlic press & $\begin{array}{l}\text { Colander, } \\
\text { Drushlag, } \\
\text { Sieve }\end{array}$ \\
\hline
\end{tabular}

The conducted research allows us to draw a number of conclusions:

There is a difference in the correctness and accuracy of the name of the subject. (The most accurate names are given by male respondents; women confuse items such as a mixer and a blender). In the word colander, both women and men are characterized by metathesis, that is, replacing letters in the syllable.

Researchers of the gender factor in speech note that it is impossible to identify the typical features of male and female speech, since there are no sharp boundaries between them, at the same time, it is possible to identify certain tendencies that are characteristic of female and male speech. Comparing representatives of two gender groups, we identified the following trends:

- The phenomenon of vocalism is inherent in women, followed by stretching of vowels, and men try to briefly pronounce the percussive sound.

- In women, assimilation by softness is noticeable and in men, the longitude of consonants prevails.

- There is a loss of vowel sounds in the syllable by men compared to the feminine.

There is a greater variety of options for the names of objects in women, for example, the word blender was designated as a mixer, juicer, coffee grinder. There is a difference in the correctness and accuracy of the name of the object: the most accurate name is given by men.

Studying the connection of language in the gender aspect requires taking into account other factors that influence the communicative behavior of men and women, such as age, education, profession, and there is also the possibility of further developing the study at other levels of the language.

The Answers of multiple choice questions of survey is given Table 2. In a conversation, different types of usage of language. 
Table 2. Different types of usage of language

\begin{tabular}{|c|c|c|c|}
\hline Options & Boys & Girls & Total \% \\
\hline Formal language & $3(12 \%)$ & $13(52 \%)$ & $32 \%$ \\
\hline Informal language & $22(88 \%)$ & $12(48 \%)$ & $68 \%$ \\
\hline
\end{tabular}

According to the results of Table 2, it can be identied that 32 percentage of total formal language users with others. Males are 12 percent, females are 52 percent, however, it can be shown, 68 percentage of total participants unitilize informal language. From these numbers, men are 88 percent and women are 48 percent. The findings of the table shows that a significant usage of formal and informal language among participants.

\section{Discussion}

The results of the communicative behaviors (verbal and nonverbal) of men and women should be considered:

\subsection{Characteristics of women's communicative behavior}

Women's speech is definitely different from men's speech. To prove this, let's first look at how women behave in a particular speech situation.

Communication in the workplace - The need for communication among many women is so great that if a woman does not talk during the work day, it will negatively affect their mood, work productivity and work quality. Some "women's" businesses have introduced 5-10 minute breaks for communication. In others, workers' desks were arranged so that they could talk without being distracted from work. These measures have proven to be economically feasible.

Goals - The communication process is very important for women. The beginning of "Let's Talk" is appropriate for talking to friends, but not for talking to a man. The woman seeks to engage or engage the interlocutor.

What are they talking about - The disadvantages of many women are gossiping, updating and even gossiping about the home. Women can talk more about their failures.

Mirrors - A woman thinks out loud what is perceived by a man as a conversationalist. Women express their feelings easily, not shyly.

Interruption of the interlocutor - The woman is less likely to interfere with the inter locutor, she prefers the interlocutor and understands his feelings.

Hearing - The woman listens very carefully. Female speech is characterized by the use of attention signals (e.g., "ya", "of course", “yes"). They play an important role in women's speech: they activate and stimulate conversation.

Facial expressions - As they talk, the women smile and look into each other's eyes.

Women rarely stumble - By comparing the results obtained in the evaluation of appearance and women's faces, most emotions (fear, disgust, joy, anger, surprise) with facial expressions are more clearly identified in women. For example, surprise - 96\%, fear - $85 \%$ in women.

The woman cheats - A woman can always deceive a man. Those who think they are special cannot be deceived: even if a woman does not lie, she is unable to hold it: she simply does not want to drive a man into a corner for fear of spoiling it with him. 
Non-verbal signals - The reason for a woman's high sensitivity to hidden subtext is her ability to sense and decode nonverbal cues: posture, gestures, body movements performed during speech. They are produced unconsciously and give the status of a speaker.

Letters - It is customary for women to give praise because they desperately need it ("women love with their ears"). When praise is not broken, men (both men and women) receive compliments and compliments, although women in general are aware of the quality of this praise. Women scholars point out that such a ridiculous statement by a man in a debate with a woman, "you are my most precious treasure" is the most compelling evidence to reassure a woman.

Criticism - Women are more critical of their role in society. But they are more inclined to form stereotypes of behavior and recognize with great difficulty that it can be improved. Women criticize their appearance.

Abbreviation - Women's speech is more intense than men's. There are so many ambiguities in women's speech that they can't see "yes", "no" and "can" at the same time. And it takes more time for the presentation. Uncertainty is caused by conditioned mood, where a woman uses 2 times more than a man. It has 5 times more restrictive phrases (e.g. "if necessary"). Women ask 3 times more questions and ask, "Aren't they?", "Yes?", "No?", "Right?" And they apologize more than men.

Tonality - Women take a painful approach to tone enhancement and place great emphasis on the tone of the conversation.

Sensitivity - Typically, a woman's speech has more emotion than a man's speech, which is manifested in the more use of vocabulary, words, metaphors, comparisons, epithets of emotional color. Women use more words to describe feelings, emotions, psychophysiological conditions. At the same time, the woman tries to avoid elements of "dating" behavior in her speech: nicknames, nicknames, and abusive treatment.

The parts of speech - Female speech has the advantages of more complex adjectives, higher adjectives, terms, and combinations. Women often use specific names in their speech.

\subsection{Characteristics of communicative behavior in men}

Communication in the workplace - Men rarely talk in the workplace because it's hard for them to do serious work and talk. Also, men don't like to be counseled, they are skeptical about reading. This is because men don't like to ask for help because it means they admit their incompetence and incompetence.

Goals - For a man, the result is important in the communication process. Men communicate better when they know the purpose of the conversation.

What are they talking about - Men talk more about work, politics and sports. Men talk more about their success. They tend to look at their friends and talk about their victories.

Mirrors - The man prefers to think in silence, only expressing the end result. Men express their feelings more harshly than women. Interruption of the inter locutor. A man mixes twice as much as a woman.

Hearing - The average man listens intently to a woman for only 10-15 seconds. A man tends to give ready advice when discussing any issue, especially without listening to the interlocutor and asking him additional questions.

Facial expressions - Men, when they are talking, often look to the side and show no emotion on their faces. 
Who is cheating? - Only a few men cheat on a woman. Basically, the woman immediately feels the lie.

Non-verbal signals - In a hidden context, men are not particularly sensitive. They do not try to reveal any gestures, facial expressions. Men focus on the topic of conversation.

Letters - It is customary to praise women, but men rarely respond positively to compliments on them, only their appearance is inferior.

Criticism - Men rarely criticize themselves. They are more confident in their appearance. The man takes the advice given to him as criticism, doubting his authority.

Abbreviation - A man's speech is shorter than a woman's because a man is stricter in his judgments. It is also harder for men to apologize than for women.

Tonality - Women have a painful approach to tone enhancement and place great emphasis on the tonality of the conversation. Men adopt a categorical tone, usually not feeling any, if they need to.

Sensitivity - Men have less emotional speech than women. Often they hide their feelings. Also, a man accepts any emotional speech with irony and suspicion, with some caution. Human speech is more careless and free.

The parts of speech - Men often use abstract horses in their speech. In a man's speech, the relative number of horses in a single sentence is much higher. It is argued that men use active vocal verbs more. They explain this by the fact that a person takes a more active position in society. There are more interrogative, imperative, and negative sentences in men's speech than in women's speech. It should be noted that women use more words than men to express ideas in a single composition.

For understanding of findings of research reveals that $88 \%$ of total participants interrupt while using a language in the conversation. Among them boys are $96 \%$ and girls are $80 \%$. On the other hand, only $12 \%$ of the total participants do not interrupt. The result of the study shows that boys interrupt more than girls and it indicates the gender difference among them. In terms of using words like "adorable", "charming", "sweet" and "lovely"- the evidence of the study shows that $86 \%$ of the total participants use those words where boys are $80 \%$ and girls are $92 \%$. On the other hand, only $14 \%$ of the total participants do not use those words. The result of the study shows that girls use those words more than boys which show the gender difference in a great extent.

\section{Conclusion}

To summarize the consideration of male and female speech behaviors, it should be noted that some factors affect any speaking person. There can be no distinction in any language itself. However, language can be utilized by individuals to accomplish a specific reason which mirrors the individual or social qualities. Limitation of the utilization of language due to the social climate makes sex contrast generally. From the examination study plainly male and female dialects are very unique. This distinction happens generally in jargon use, voice and tone, syntactic construction and way of utilizing language. Additionally, there are some regular contrasts and some normal similitudes in utilizing language. The exploration study shows that in late time the adolescent are rehearsing these distinctions in an enormous degree. While expressing a language their various methods of utilizing language mirrors the sex contrast. The utilizing of language diversely likewise makes numerous varieties in correspondence. At long last it ought to be brought up that the way is as yet perpetual for analysts to uncover increasingly more point by point distinction among male and female language.

Of course, the main factor is the gender of the speaker: "Women are more prone to pronunciation speech movements; they are more easily exchanged, "changing" roles in the act of communication [15]. It is carried out by the subject under discussion, they do not respond to comments that are not 
relevant to it. In men's speech, terminology, desire for accuracy of nominations, the strong influence of the "profession" factor, the tendency to use expressive, especially stylistically abbreviated means and intentional distortion of speech has also been reported. According to the authors, fanaticism is used by both men and women in same-sex groups. However, it is not acceptable to pronounce it in mixed groups. The authors attribute the typical features of female speech to hyperbole expressiveness (terrible insult) "Ah!" "Oh!" for describe the frequent use of such expressions. An associative area in male and female speech is related to different parts of the picture: sports, hunting, professional, military fields (for men) and nature, animals, the everyday world around (for women). Women's speech reveals a large concentration of emotionally-charged vocabulary. There are stylistically abbreviated swear words in men's speech.

A comparison of the speech characteristics of men and women allows us to draw the following conclusions:

1. More women than men emphasize relationships with people of the opposite sex.

2. Women are usually more interested in other people than men.

3. More women than men are interested in the quality of the scene, the people, the things.

4. Women are more interested in the present and the future, men are more interested in the past.

5. Women pay more attention to the content of what they want to address the interviewer than men.

\section{References}

Anthology of the course "Fundamentals of Gender Research” I. Chikalova, M. MCGI, (2000).

Babalola, J., \& Oyinloye, G. (2012). Language and Gender Distinctions. International Review of Social Science and Humanities, 2(2), P. 236-242.

Boe, S. (1987). Language as an Expression of Caring in Women. Anthropological Linguistics, 29(3), 271-285.

Belyaev, Yu. A. (2000). Speech and speech behaviors of men and women. M. EXMO-Press Publishing House.

Cameron, D. (2003). Gender and Language Ideologies. Oxford: Blackwell.

Crawford, M. (1995). Talking Difference - on gender and language. SAGE.

Finch, G. (2003). Word of Mouth. Palgrave. Haas, A. (1979). Male and Female Spoken Language Differences: Stereotypes And Evidence. Psychological Bulletin, 86(3), 616-626.

Holmes, J. (1986). Functions of You Know in Women's and Men's Speech. Language in Society, $15(1), 1-21$.

Karlsson, S. (2007). Gender- related Differences in Language Use.

Kirilina, A.V. (2005). Gender issues in linguistics // Gender and language. M, Volume 13

Lakoff, R. (1975). Language and Woman's Place. Language in Society, 2(1), 45-80. New York: Harper and Row.

Mei-rong, W., \& Ching-yu hsieh, S. (2007). Gender Differences in the Language for Emotions. Asian Journal of Management and Humanity Sciences, 2(1-4), 89-97. 
Nemati, A., \& Bayer, J. M. (2007). Gender differences in the use of linguistic forms in the speech of men and women: A comparative study of Persian and English. Language in India, 7(9), 1-16.

Popova, E.A. On the features of men’s and women's speech // Russian speech. - 2007, - № 3. - P. 4049.

Kesik, F., \& Aslan, H. (2020). Metaphoric expressions of the students about the concept of happiness. Educational Administration: Theory and Practice, 26(2), 303-354.

Skazhenik, E.N. (2006). Gender aspects of communicative behavior // Textbook for Entrepreneurship. TRTU.

Telia, V.N. (1991). The human factor in language: Linguistic mechanisms of expressiveness $-M$. Nauka, P. 32-33.

Tannen, D. (1990). You just don't understand: Women and men in conversation. New York: Ballantine.

Yıldız, B., \& İnceoğlu, G. (2020). Mathematics teacher candidates' conceptual knowledge of the concept of limit in single-variable functions. Turkish Online Journal of Qualitative Inquiry, 11(4), 511-532.

Talbot, M. (1998). Language and Gender- An Introduction. Polity Press.

Wenjing, X. (2012). Study on gender differences in English. International Conference on Education Technology and Management Engineering, 16-17, P. 218-221.

http: //ru.wikipedia.org/

\section{AUTHORS BIODATA}

Dilshodbek Rustamov is currently working from Andijan State university Republic of zbekistan.

Shokhida Shakhabitdinova is currently working from Andijan State university Republic of zbekistan.

Sobirjon Solijonovc is currently working from Andijan State university Republic of zbekistan.

Abdulaziz Mattiyev is currently working from Andijan State university Republic of zbekistan.

Shakhobiddin Begaliyev is currently working from Andijan State university Republic of zbekistan.

Shakhram Fayziev is currently working from Editor at Portal International Scientific Journals Tadqiqot.uz. 